\title{
EDITORIAL Perdemos o Relator da "oitava" ESPECIAL
}

SPECIAL EDITORIAL

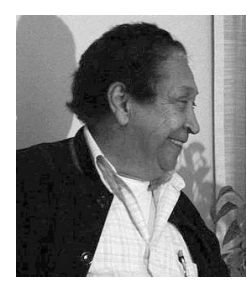

O Professor Guilherme Rodrigues da Silva morreu na mesma semana em que celebramos vinte anos de realização da VIII Conferência Nacional de Saúde. A "oitava", assim mesmo em caixa baixa demonstrando que já se tornou um glorioso substantivo comum. Esta homenagem não deve ter o ranço de um necrológio, mas de celebração de uma vida plena de realizações de um mestre no sentido magno da palavra.

Resistimos muito a editar as diversas manifestações que nos chegaram no dia 11 de março de 2006 e em dias subseqüentes. Corríamos o risco de eleger uma ordem criticável: decidimos alinhar as manifestações à medida que chegaram ao conhecimento do Corpo Editorial da Revista Brasileira de Epidemiologia. Com uma única exceção: iniciamos com as regras do jogo:

"Todos,

Guilherme, entre muitas outras atividades, foi Presidente da Abrasco e pertencia ao corpo editorial da nossa Revista Brasileira de Epidemiologia (Abrasco). No número 9(1) deste março 2006 vamos dar uma Notícia de Falecimento, associada a homenagem na seção "Gavetas e Prateleiras", republicando seu texto "La formación de personal en funcion de los usos y perspectivas de la Epidemiologia” , de 1984.

Todos os textos manifestando pesar que nos chegarem até 24 de março serão incluídos neste número da RBE. Os que chegarem após essa data, no número 9(2) de junho 2006. Publicaremos todos os que chegarem ao endereço da abrasco@ensp.fiocruz.br ao endereço da RBE revbrepi@usp.br ao endereço do Editor jrcarval@usp.br ou jrcarval@fiocruz.br

Aguardamos suas manifestações,

Carvalheiro."

A maioria das mensagens nos chegou através da Coordenadora de Comunicação Social da Fiocruz, Chris Tavares.

Wilma Gavrichevsky

Uma notícia triste:

"Faleceu esta madrugada o Professor Guilherme Rodrigues da Silva, um dos fundadores da Saude Coletiva no Brasil e na AL. O velório será na Faculdade de Medicina da USP e o enterro amanhã saindo de lá. Por favor avisem seus departamentos e instituições

Lilia"

"Morre um dos líderes do movimento sanitário brasileiro $\mathrm{O}$ médico sanitarista Guilherme Rodrigues da Silva, professor emérito da Universidade de São Paulo, morreu neste sábado (11/03), aos 78 anos, vítima de aneurisma na região do abdômen. Ele era considerado um "guru" pelo grupo que, nos anos 60 e 70, deu origem à chamada medicina preventiva no Brasil Chris Tavares"

\section{"Cristina,}

mais um dos que ajudaram a fazer a cabeça de nossa geração de sanitaristas se vai. Que permaneça em nossa memória a sua lembrança a reforçar nossos compromissos com a saúde pública.

Paranaguá" 
"Cristina,

El Dr. Guillerme jugó un papel fundamental en la formación, no solo de los brasileños, sino del pensamiento médico social de América Latina. Considero que el Dr. Guillerme continuará presente como parte de nuestro quehacer diario.

Edmundo Granda

egranda@ecu.ops-oms.org"

"Aos amigos de Guilherme Rodrigues, à comunidade da Saúde Coletiva, a todos nós em luto.

A Universidade Federal da Bahia une-se ao pranto pelo falecimento de Guilherme Rodrigues da Silva. Guilherme foi um docente querido e reconhecido da Faculdade de Medicina da UFBA, onde destacouse como pioneiro pesquisador nos campos da Epidemiologia e da Saúde Comunitária. Foi em nossa universidade um dos fundadores da área da Medicina Preventiva, origem do grupo que, tendo em Guilherme um carinhoso padrinho, constitui o Instituto de Saúde Coletiva. Em todos os momentos importantes da curta porém intensa história do ISC, Guilherme foi sempre para nós um sábio, modesto e querido mestre. Sem ele, ficamos um pouco órfãos, como muitos ex-discípulos da comunidade da Saúde Coletiva, que inspirada por Guilherme, já tem grandes sucessos a comemorar, como este complexo sistema social de saúde, o SUS, que nos seus limites e carências oferece cobertura de saúde à população. Isto é apenas uma parte do importante legado de Guilherme Rodrigues da Silva à nação brasileira.

Salvador , 12/03/2206

Naomar de Almeida Filho

Reitor da UFBA

Maria da Glória Cruz Teixeira

Diretora do Instituto de Saúde Coletiva”

"Querida Cris e amigos

A morte do professor Guilherme Rodrigues da Silva, afasta de nós mais um amigo e priva a saúde brasileira de uma grande pensa- dor ,formulador ,professor,mas também de um homem que não se recusou a assumir desafios práticos na gestão de unidades do sistema de saúde e da educação médica. Devemos todos que lutamos e nos responsabilizamos pela Reforma Sanitária brasileira reconhecimento a este grande ser humano.Quem sabe em algum canto ele e o Arouca não estão nos olhando e ,tomando um chope celestial,dando uma força

Dr. Luiz Antônio Santini

Diretor Geral INCA

lsantini@inca.gov.br"

"Chris, por favor, transmita a mensagem abaixo para a família do Dr. Guilherme e para a comunidade de Saúde Coletiva.

Obrigada, um beijo

Sarah

Em nome da Diretoria Nacional do Centro Brasileiro de Estudos de Saúde (Cebes) e em meu nome pessoal manifesto meu pesar com o falecimento do Prof. Guilherme Rodrigues da Silva ocorrida no dia de ontem. Dr. Guilherme foi um grande professor, um profissional de saúde militante, um bravo brasileiro. O conheci como professor do DMP/USP. Tive grande admiração por sua coragem de assumir a Superintendência do Hospital das Clínicas na década de 80. A última vez em que estivemos juntos foi na comemoração dos 25 anos da Abrasco na qual compareceu como ex-presidente da entidade. A lembrança mais querida é de sua participação na minha banca de mestrado quando debateu minha análise do Ministério da Saúde na década de 70.

Sentiremos saudades.

Sarah Escorel

Presidente

p/ Diretoria Nacional

Centro Brasileiro de Estudos de Saúde (Cebes)"

“Carva,

Tive a distinção de ter o Prof. Guilherme em minha banca para Professor Titular da 
ENSP e também de ter sido por ele convidado para integrar bancas de concursos e de posgraduação da Faculdade de Medicina da USP. Na ocasião de sua morte quero me associar ao pesar da grande família de epidemiologistas e preventivistas brasileiros.

Eduardo de Azeredo Costa”

"Carva,

Segue a nota.

Ao me solidarizar e manifestar meus sentimentos à família do Prof. Guilherme, ressalto a perda que todos nós vivenciamos. O professor Guilherme soube, como poucos, enfrentar todas as dificuldades (que não foram poucas e nem de pequena monta) que se lhe apresentaram no meio acadêmico. Com sua determinação, sabedoria e inteligência tratou delas como objeto de aprendizado e ensino e criatividade. Foi generoso ao nos dispor de capacidade de criação, investigação e multiplicação, ensinando e formando geração de sanitaristas. Fecha um importante ciclo do movimento sanitário brasileiro.

Que nos sirva de exemplo!!!

Moisés Goldbaum

Departamento de Medicina Preventiva Faculdade de Medicina da USP"

"Prezado Jrcarval,

Eis o texto do nosso Depto.

A livre-docência foi em 1960.

Ele nasceu em Mucugê, BA, aos 10 de fevereiro (2006-78 anos)

A data do mestrado não sei exatamente. Não achei nos exemplares dos seus CVs que consultei.

Na FM da UFBA ele foi professor assistente da Catédra de Propedêutica Médica.

Um grande abraço

Euclides

GUILHERME RODRIGUES DA SILVA, nosso e sempre PROFESSOR.

Do Professor Guilherme, poderíamos lembrar que, formado em Medicina pela
Universidade Federal da Bahia, em 1953, fez seu mestrado em Saúde Pública na Universidade de Harvard, nos Estados Unidos. Após sua Livre-Docência, também na Universidade Federal da Bahia, veio para São Paulo, em 1967, realizar o concurso para a Cátedra de Medicina Preventiva, iniciando sua carreira acadêmica entre nós. Poderíamos também recordar que foi Superintendente do Hospital das Clínicas da Faculdade de Medicina da Universidade de São Paulo, maior hospital público do País e referência para muitas áreas da Medicina, ou que recebeu o título de Professor Emérito da nossa Escola. Mas estas considerações nos recordariam apenas da parte mais formal de sua trajetória.

O que gostaríamos de destacar são suas qualidades, como pessoa e profissional, de empreendedor e grande humanista, qualidades que o acompanharam e marcaram sua presença ao longo de todo tempo em que esteve conosco. Seja pelo fato de, ao vir para São Paulo, ter inaugurado a Cátedra de Medicina Preventiva na Faculdade de Medicina da USP, e a própria Medicina Preventiva na Casa de Arnaldo, seja por ter estruturado, já nos idos de 1960, o Núcleo de Medicina Preventiva do Hospital Universitário Professor Edgard Santos, raiz histórica do Instituto de Saúde Coletiva da Universidade Federal da Bahia, a figura de um grande empreendedor e ousado pioneiro se destaca.

Nesses gestos e outros tantos, estruturando a Epidemiologia brasileira, a pósgraduação em Saúde Coletiva, os programas docente-assistenciais, nosso Professor Guilherme travou difíceis e complexas batalhas contra arraigadas tradições e conservadorismos, no plano institucional e científico. Dessas batalhas, nem sempre com êxitos imediatos, nutriu-se e cresceu vigoroso o campo da Saúde Coletiva e Saúde Pública no Brasil, com forte influência por toda a América Latina. É que seus empreendimentos e ousadias estavam permeados por sua permanente preocupação com a justiça social, aliada à postura ativa que sempre adotou no combate às desigualda- 
des sociais e às iniqüidades de toda ordem. Com esta qualidade de humanizador é que queremos, principalmente, lembrá-lo. Homem de ciência, que se manteve continuamente atualizado, dominando temas que vão dos modelos matemáticos à relevância da Genética para a Epidemiologia, nosso Professor, desde os tempos de ditadura militar até o presente tempo de ditadura do mercado, perfilou-se clara e ativamente em favor da democracia, da universalização dos cuidados, da eqüidade, da participação popular na assistência e do Sistema Único de Saúde. Educador, diante das atitudes científicas e pedagógicas mais conservadoras, não hesitou em optar pela interdisciplinaridade, em abrir espaços institucionais e científicos para o diálogo com as ciências sociais e humanas e o trabalho conjunto com cientistas sociais. Também não temeu, ao contrário abraçou, a necessidade de aliar ao ensino técnico-científico dos alunos de Medicina o ensino para a vida social, pela experiência pedagógica do contato direto dos futuros médicos com a dramática desigualdade de que é feita também a nossa realidade brasileira.

Por tudo isso queremos lembrá-lo, e dizer a todos quanta falta nos fará. Se hoje os saberes interdisciplinares e as práticas multiprofissionais encontram-se plenamente consolidados num campo científico e institucional, que se mostra maduro e presente inclusive no plano internacional, é porque as raízes e origens desse campo já são História. Nosso Professor inaugurou e fez esta História.

Março de 2006,

Departamento de Medicina Preventiva da Faculdade de Medicina da USP."
"Há 20 anos, a Oitava Conferência Nacional de Saúde mobilizava o Brasil (Fragmento) Ricardo Valverde Nesta quinta-feira (16/03) completam-se 20 anos da solenidade de abertura da $8^{a}$ Conferência Nacional de Saúde, um evento que mobilizou e ajudou a mudar o Brasil naquele momento em que o país se redemocratizava e voltava a respirar ares de liberdade. Um dos objetivos da conferência foi alcançado esta semana, quando o Ministério da Saúde empossou os 17 membros da Comissão Nacional sobre Determinantes Sociais em Saúde (CDSS), um projeto sonhado por ícones do movimento sanitarista brasileiro, como Sergio Arouca, Carlos Sant'Anna, Guilherme Rodrigues Silva, Samuel Pessoa, Josué de Castro e Cecília Donnangelo, e que agora se torna realidade. Duas décadas depois a conferência continua a dar frutos, conseqüência das sementes que plantou.”

"Chris,

Não esqueça que o Prof. Gullherme Rodrigues da Silva foi o Relator da "oitava”!!!!

bjs

Euclides"

"Euclides \& Chris,

Este vai ser o título do Editorial especial da Revista Brasileira de Epidemiologia: "Perdemos o Relator da Oitava".

Carvalheiro".

“Grande Carva

bjs

Chris" 